\title{
Dissolution of Biodiesel Precipitates via Ultrasound
}

October 2012

Prepared by

Mike Kass

Maggie Connatser

Samuel A. Lewis, Sr.

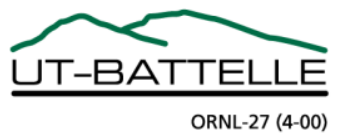




\title{
DOCUMENT AVAILABILITY
}

Reports produced after January 1, 1996, are generally available free via the U.S. Department of Energy (DOE) Information Bridge.

Web site http://www.osti.gov/bridge

Reports produced before January 1, 1996, may be purchased by members of the public from the following source.

\author{
National Technical Information Service \\ 5285 Port Royal Road \\ Springfield, VA 22161 \\ Telephone 703-605-6000 (1-800-553-6847) \\ TDD 703-487-4639 \\ Fax 703-605-6900 \\ E-mail info@ntis.gov \\ Web site http://www.ntis.gov/support/ordernowabout.htm
}

Reports are available to DOE employees, DOE contractors, Energy Technology Data Exchange (ETDE) representatives, and International Nuclear Information System (INIS) representatives from the following source.

Office of Scientific and Technical Information

P.O. Box 62

Oak Ridge, TN 37831

Telephone 865-576-8401

Fax 865-576-5728

E-mail reports@osti.gov

Web site http://www.osti.gov/contact.html

This report was prepared as an account of work sponsored by an agency of the United States Government. Neither the United States Government nor any agency thereof, nor any of their employees, makes any warranty, express or implied, or assumes any legal liability or responsibility for the accuracy, completeness, or usefulness of any information, apparatus, product, or process disclosed, or represents that its use would not infringe privately owned rights. Reference herein to any specific commercial product, process, or service by trade name, trademark, manufacturer, or otherwise, does not necessarily constitute or imply its endorsement, recommendation, or favoring by the United States Government or any agency thereof. The views and opinions of authors expressed herein do not necessarily state or reflect those of the United States Government or any agency thereof. 
Energy and Transportation Science Division

\section{DISSOLUTION OF BIODIESEL PRECIPITATES VIA ULTRASOUND}

Mike Kass

Maggie Connatser

Sam Lewis

Date Published: October 2012

Prepared by

OAK RIDGE NATIONAL LABORATORY

Oak Ridge, Tennessee 37831-6283

managed by

UT-BATTELLE, LLC

for the

U.S. DEPARTMENT OF ENERGY

under contract DE-AC05-00OR22725 


\section{CONTENTS}

Page

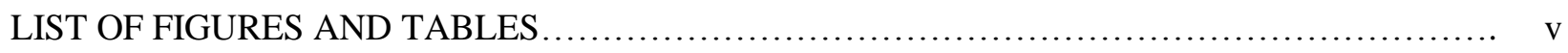

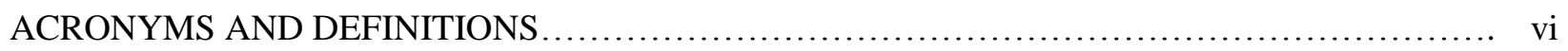

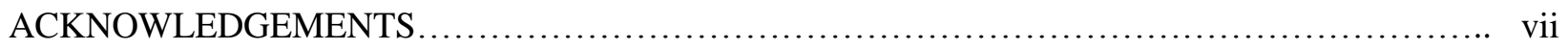

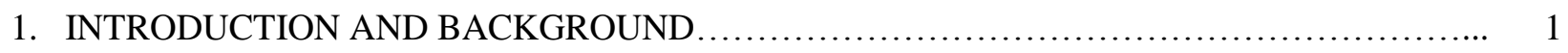

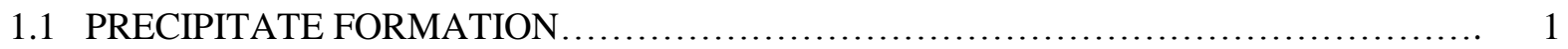

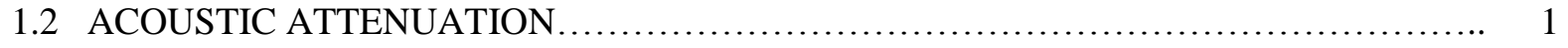

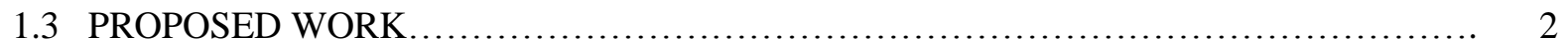

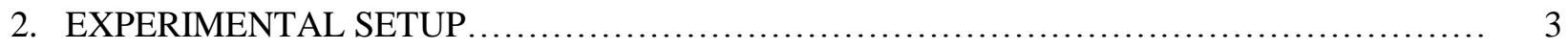

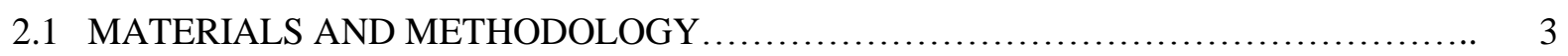

2.2 EXPERIMENTAL APPARATUS ..................................................... 4

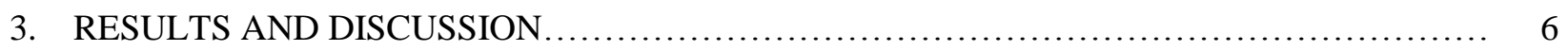

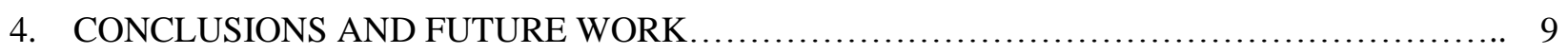

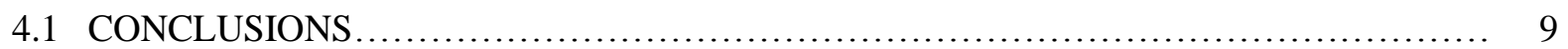

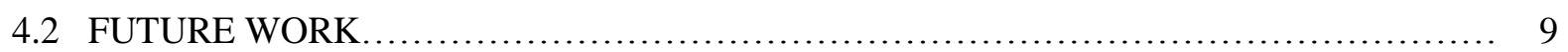

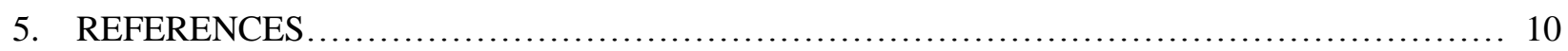




\section{LIST OF FIGURES AND TABLES}

Figure

Page

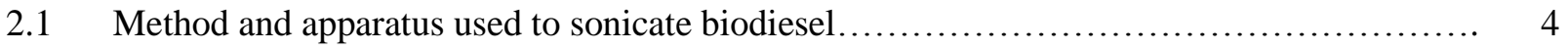

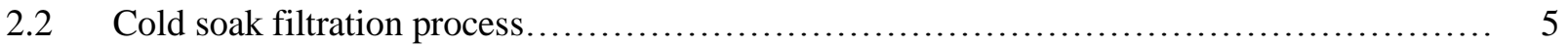

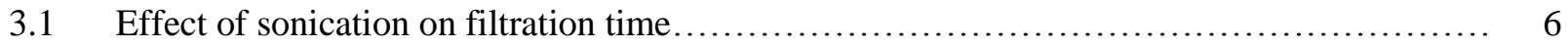

3.2 Filtration time results for biodiesel for each test condition ............................ 7

3.3 GC-MS results for untreated and sonicated biodiesel................................. 8

\section{Table}

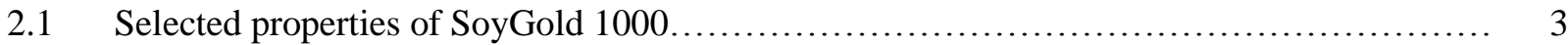

3.1 Molecular area ion counts for biodiesel methyl esters................................. 8 


\section{ACRONYMS AND DEFINITIONS}

ASTM

B20

B100

DOE

FEERC

GC-MS

MG

ORNL

SDS

SG

SME
American Society for Testing and Materials

diesel fuel containing 20 vol.\% biodiesel

neat biodiesel

U.S. Department of Energy

Fuels, Engines, and Emissions Research Center (ORNL)

gas chromatography-mass spectrometry

Monoglyceride

Oak Ridge National Laboratory

sodium dodecylsulfate

steryl glucoside

soy methyl ester 


\section{ACKNOWLEDGEMENTS}

This report and the work described were sponsored by Kevin Stork from the U.S. Department of Energy (DOE) Office of Energy Efficiency and Renewable Energy Vehicle Technologies Program and the seed money committee of the Oak Ridge National Laboratory (ORNL). The authors would like to acknowledge Scott Sluder of the Oak Ridge National Laboratory (ORNL) for providing the test fuels and Bob McCormick of the National Renewable Energy Laboratory for providing additional insight and direction. 



\section{INTRODUCTION AND BACKGROUND}

Recently there has been renewed interest in expanding the role of biodiesel in the energy plan for the United States. With the rising cost of petroleum and the recognized need to utilize domestic fuel resources to improve the nation's energy security, biofuels, such as biodiesel, offer a promising alternative to help meet the country's energy needs (especially for transportation). Additional concerns about global warming have also led to calls for more renewable energy sources, including alternative fuels. Biodiesel is made from renewable resources such as soybean oil, other plant oils and animal fat. It can be used in diesel engines and burners (to heat homes) with few or no modifications and can be used either neat (B100), or blended with petroleum diesel (commonly as $20 \%$ biodiesel, B20).

\subsection{PRECIPITATE FORMATION}

Although biodiesel has excellent compression ignition fuel properties and is known to lower particulate matter emissions, at temperatures below the cloud point $\left(\sim 5^{\circ} \mathrm{C}\right)$ biodiesel begins to solidify and flow properties quickly degrade. Unfortunately, biodiesel has been demonstrated to also plug filter systems when it has been exposed to temperatures just above the cloud point. The cause of the plugging is the formation of precipitates which are stable at ambient temperatures $\left(20\right.$ to $40^{\circ} \mathrm{C}$ or 68 to $\left.104^{\circ} \mathrm{F}\right)$ and cannot be detected by visual inspection (1). Lack of visual detection indicates that precipitates are on the order of several molecular lengths in size. The kinetics and chemistry of these precipitants are currently being investigated. Some studies have suggested that these precipitates were solidified saturated monoglycerides. However, Pfalzgraph et al performed a detailed study which suggests that these precipitants likely form during the interaction of several constituents, with steryl glucosides as a necessary component. In fact studies have shown that the level of precipitates seems to be higher for blends of biodiesel and diesel fuel than with biodiesel alone. This problem is a critical area of research in the biodiesel community and was considered the top issue at the 2007 Biodiesel Technical Workshop (2).

To better understand the susceptibility of biodiesel to precipitate formation (and hence filter plugging), a cold soak filtration test (ASTM D6217) was developed by the American Society for Testing Materials, which has become the industry standard for assessing the filterability of biodiesel fuels.

\subsection{ACOUSTIC ATTENUATION}

A propagating acoustic wave can be reflected or absorbed by particulate matter (solid or fluid) depending on the size of the wavelength relative to the dispersed particle (3). Long wavelengths relative to the size of the object are absorbed rather than reflected. Because the precipitate micelles are on the order of several molecular lengths in size, high energy ultrasonic frequencies up to $100 \mathrm{~Hz}$ would be effectively absorbed by the dispersed precipitate micelles. A study by Tat et al. (1) showed that the speed of sound in MSE biodiesel is around $1400 \mathrm{~m} / \mathrm{s}$. Therefore, a standard laboratory sonifier outputting $20 \mathrm{kHz}$ of fixed acoustic energy would have a wavelength of $7 \mathrm{~cm}$ in neat biodiesel and at that wavelength, the ultrasonic waves would be readily absorbed by the precipitate micelles. Generally speaking, absorption is the conversion of acoustic energy to thermal energy. The interfacial equilibrium between the precipitate micelle and the surrounding fluid is altered by the incoming acoustic wave. Viscous damping of the precipitate motion combined with heat conduction into the precipitant will raise the temperature of the precipitate relative to the bulk liquid. In other words thermoviscous effects that occur on the precipitant surface will result in preferential heating of the precipitated phases. 


\subsection{PROPOSED WORK}

Although other researchers are currently investigating the chemistry of biodiesel precipitates, we are not aware of any effort to address precipitate removal after they have formed. Because filter plugging (caused by precipitate buildup) is the leading technical barrier to expanded biodiesel usage, cost-effective solutions to remove precipitates have the potential to advance biodiesel use as a transportation fuel.

This study seeks to remove precipitates by performing in-situ dissolution in neat biodiesel (B100). In order to induce and control precipitate formation, high quality B100 will be doped with trace levels of steryl glucoside, sodium dodecylsulfate, and water. These chemicals have been demonstrated by Pfalzgraf et al. (4) to be effective precursors of biodiesel precipitates. The doped B100 fuel would be chilled to induce precipitate formation and then subjected to $20 \mathrm{kHz}$ of sonic energy. The influence of ultrasonic energy on precipitate dissolution will be evaluated based using the method described by the ASTM standard test method for cold soak filtration (5).

Using high-intensity sound waves, it is theoretically possible to keep the bulk fluid temperature relatively low while selectively heating the precipitates to force them back into solution. In contrast, conventional heating (using resistance heaters or furnaces) will heat up the entire bulk fuel, thereby causing oxidation and degradation of the methyl ester chains that make up biodiesel. In order to develop a method to mitigate fuel filter clogging caused by precipitates formation at low ambient temperatures, we have initiated experiments to investigate the use of ultrasonic energy to redissolve these precipitates and return the biodiesel to acceptable filterability.

This report describes a bench-scale proof-of-concept effort performed by the ORNL to investigate the effects of sonication on the removal of induced biodiesel precipitates. 


\section{EXPERIMENTAL SETUP}

\subsection{MATERIALS AND METHODOLOGY}

The biodiesel product used in this study was SoyGold 1000 industrial solvent (manufactured by SoyGold). SoyGold 1000 is a high-grade biodiesel composed of soybean methyl esters. Key properties of SoyGold 1000 are listed below in Table 1 (6).

Table 2.1 Selected properties of SoyGold 1000.

\begin{tabular}{|l|c|}
\hline \multicolumn{1}{|c|}{ Property } & Value \\
\hline Low volatile organic compounds (VOC), $\%$ & 7.29 \\
\hline Kauri butanol value & 61 \\
\hline Specific gravity, $\mathrm{g} / \mathrm{mL}$ & 0.882 \\
\hline Boiling point, ${ }^{\circ} \mathrm{C}$ & 333 \\
\hline Flashpoint, ${ }^{\circ} \mathrm{C}$ & $>150$ \\
\hline
\end{tabular}

Untreated SoyGold B100 biodiesel was sonicated initially to rule out any non-additive related changes in filter times. This step is necessary since SoyGold 1000 contains 0.17 to $0.24 w t . \%$ of monoglyceride (MG) compounds (7). Therefore, it is important to remove any pre-existing MG precipitates and/or isolate their contribution to the time required to pass the biodiesel through the filter. Because high intensity ultrasound can generate significant levels of thermal energy, it was necessary to pulse the sonifier to prevent excessive heating. The temperature rise during sonication was measured using a thermometer and reached a bulk temperature of $66^{\circ} \mathrm{C}$. In order to separate the bulk thermal effect from the sonication-induced thermovisous contribution, an unsonified control specimen was heated to $66^{\circ} \mathrm{C}$ via a hot plate for comparison.

The combination and levels of components used in this study (20ppm SG, 40ppm SDS, and 500ppm water) were based on the formulation used by Pfalzgraf et al. (4) which resulted in the highest filter time with no added MG. The procedure to add the spiked components to the neat biodiesel was as follows:

1. First, steryl glucoside (SG) was added at $10 \%$ in pyrene to reach $20 \mathrm{ppm}$ weight/volume biodiesel. The resulting SG/pyrene blend was subsequently added to neat biodiesel and the fuel mixture was stirred and heated to $90^{\circ} \mathrm{C}$ under vacuum for 30 minutes to remove excess pyrene.

2. Next, 40ppm sodium dodecylsulfate (SDS) and 500ppm water were combined and stirred into the SG-spiked biodiesel at $70^{\circ} \mathrm{C}$ for 20 minutes in a nitrogen environment. Once the spiked fuel reached room temperature, it was placed in the refrigerator or analyzed for filtration rate, depending on the experiment being done. Unspiked control samples were placed directly into the refrigerator. After 16 hours at $2.8^{\circ} \mathrm{C}$ in the refrigerator, the samples were removed and allowed to come to room temperature over two hours, which was checked daily to be $24 \pm 1^{\circ} \mathrm{C}$.

Acoustic energy was applied 70ml biodiesel samples using a Branson 450 watt $20 \mathrm{kHz}$ sonifier as shown in Fig 2.1. To minimize bulk heating, the sonifier was operated for 40 seconds, turned off for 30 seconds and then operated for another 30 seconds. Using this approach, the maximum temperature reached was $66 \pm 2^{\circ} \mathrm{C}$. Thermal control tests were performed by heating clean biodiesel to $68^{\circ} \mathrm{C}$ (using a hot plate) in atmospheric conditions. The heated sample was removed from hot plate and allowed to cool to room temperature. 


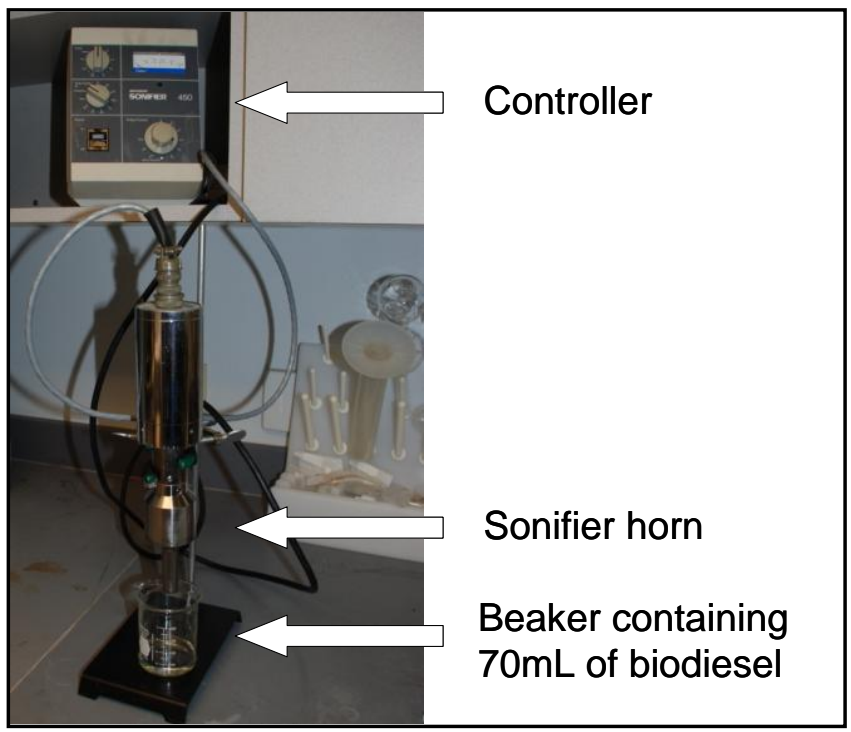

Fig. 2.1. Method and apparatus used to sonicate biodiesel.

\subsection{EXPERIMENTAL APPARATUS}

The experimental apparatus used for the cold soak filtration measurement is shown in Fig. 2.2. The apparatus was assembled using the ASTM D 7501 cold soak filtration standard. The ASTM procedure however was modified by reducing the sample fluid size passing though the filter. The reduction in sample volume decreases the filtration time but should not affect the comparison of the performance of the samples within this study. For each sample, three specimens were evaluated to assess variance. The total sample size was $70 \mathrm{~mL}$ and filtration times were measured for $50 \mathrm{~mL}$ (of the $70 \mathrm{~mL}$ ) to pass through a Whatman glass fiber filter (GFF, Cat. No. 1825-047). This procedure followed the standard filtration setup based on Pfaltzgraf's modification of the ASTM method (4). 


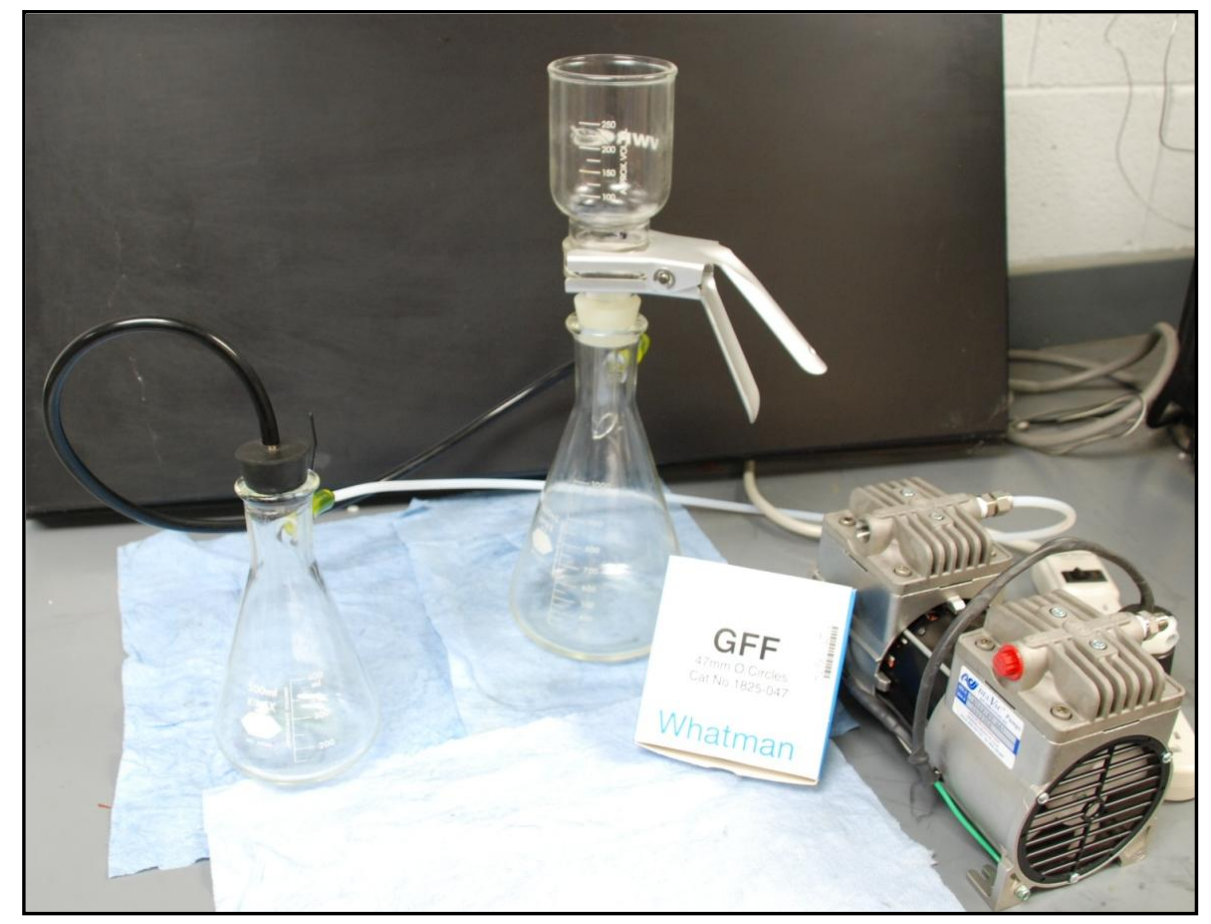

Fig 2.2. Cold soak filtration apparatus. 


\section{RESULTS AND DISCUSSION}

A sample of unspiked biodiesel was sonicated and the filtration result was compared to untreated biodiesel and a thermal control (heated to $66^{\circ} \mathrm{C}$ ). The results presented in Fig. 3.1 show that the application of sonic energy reduced the filtration time by $19 \%$ from the original condition. This result suggests that some level of precipitates were present in the as-received biodiesel, which is not surprising since all commercial biodiesels contain precipitate precursors. The data in Fig. 3.1 also show that the application of heat alone will not improve filtration time. Both the sonicated and the thermal control specimens underwent bulk heating to $66^{\circ} \mathrm{C}$, but only sonication effectively reduced filtration time. Therefore, the results indicate that the thermoviscous effects associated with that application of acoustic energy were responsible for the improved filtration times. In fact the slight increase in filtration time associated with the thermal control may be caused by the partial oxidation of the methyl ester compounds. The oxidized fuel molecules are larger than the starting methyl esters, thereby increasing the filtration time considerably.

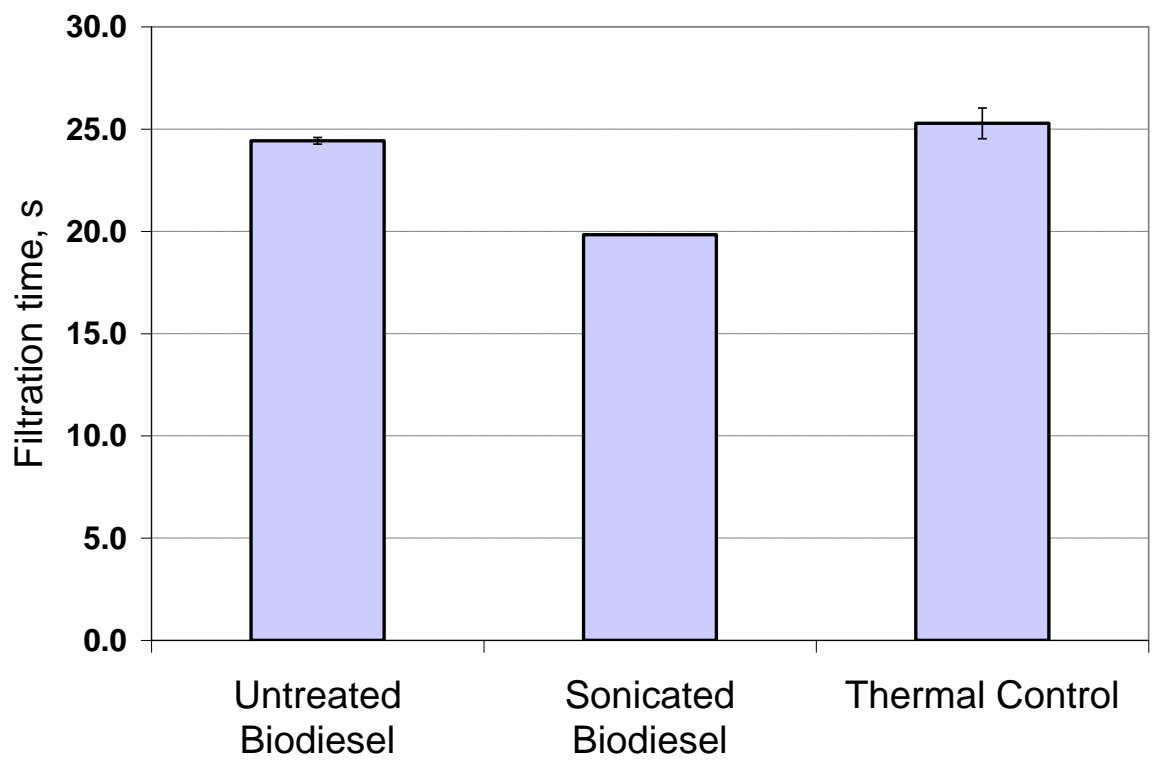

Fig 3.1. Effect of sonication on filtration time.

Biodiesel samples were subjected to combinations of sonication and refrigeration as to assess the influence of the applied sonication and filtration time. The conditions for each biodiesel sample were:

1. Original untreated condition,

2. Sonicated,

3. Sonicated followed by refrigeration,

4. Sonicated followed by spiked,

5. Sonicated followed by spiked followed by refrigeration, and

6. Sonicated followed by spiked followed by refrigeration followed by sonication.

Because sonication was found to improve the filtration time of the untreated biodiesel, this initial step was included on all samples to minimize the effect of any pre-existing precipitates. These results are shown in Fig. 3.2. The original sonicated biodiesel was refrigerated to determine if the filtration time increased to 
the original setting. Interestingly, refrigeration did not increase filtration time; in fact, refrigerating the samples slightly reduced the filtration time. The cause for the lack of change of filtration time is not known, but it appears that sonication may permanently alter the precipitate structure so that the precipitate can no longer form upon cooling. Spiking the sonicated biodiesel causes a moderate increase in filtration time as shown. When the spiked biodiesel is refrigerated, the filtration time increases by $24 \%$ (and approaches the original filtration time value) which is consistent with the formation of precipitates. However, the application of sonication to the spiked and refrigerated biodiesel effectively decreases the filtration time to the level approaching the original sonicated value.

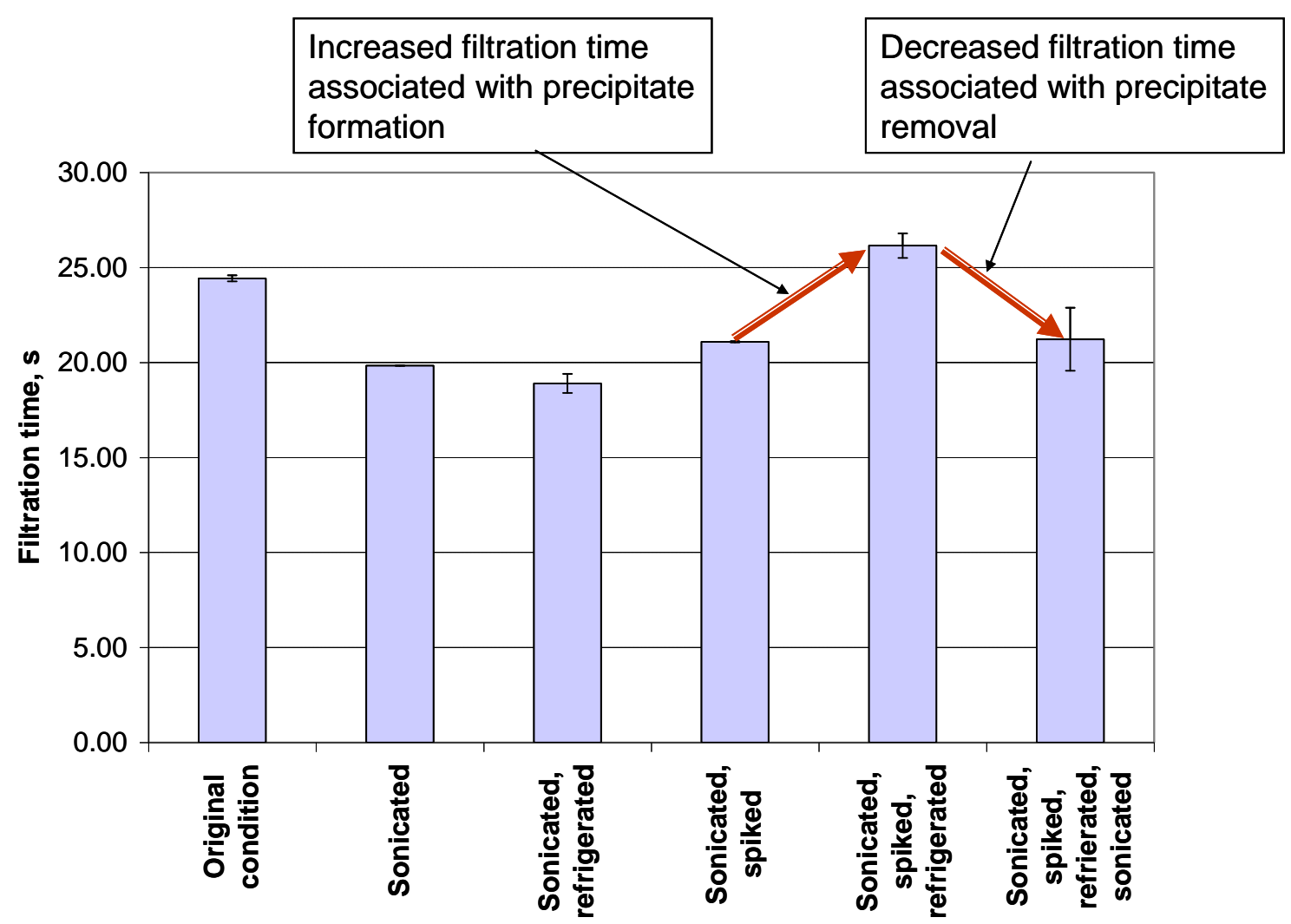

Fig. 3.2. Filtration time results for biodiesel for each test condition.

In addition to redissolution of the precipitates, the effect of sonication may also crack the methyl ester molecular chains into smaller compounds, which, theoretically, would be able to pass more readily through the filter, thereby lowering filtration time. In order to determine whether significant molecular cracking occurred, a gas chromatography-mass spectrometry (GC-MS) analysis was performed on the untreated and sonciated biodiesel. The GC-MS results are shown in Fig. 4 and the corresponding molecular counts associated with the key methyl ester groups are shown in Table 1. The data indicated that there was no significant structural change of neat biodiesel associated with sonication. 


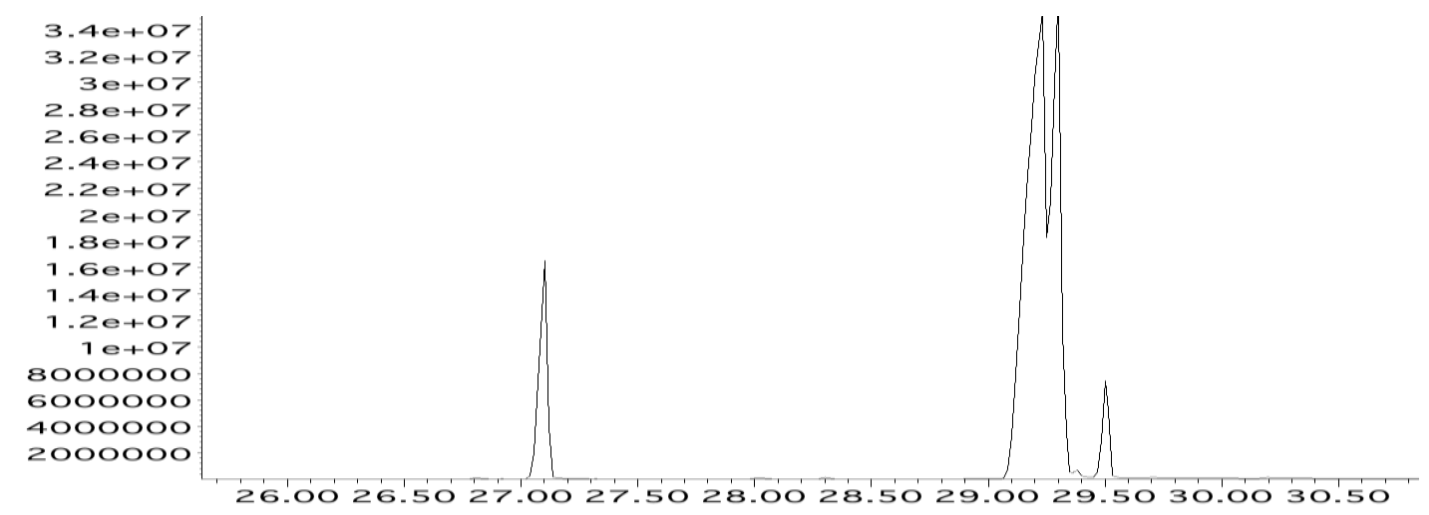

(a) Untreated B100

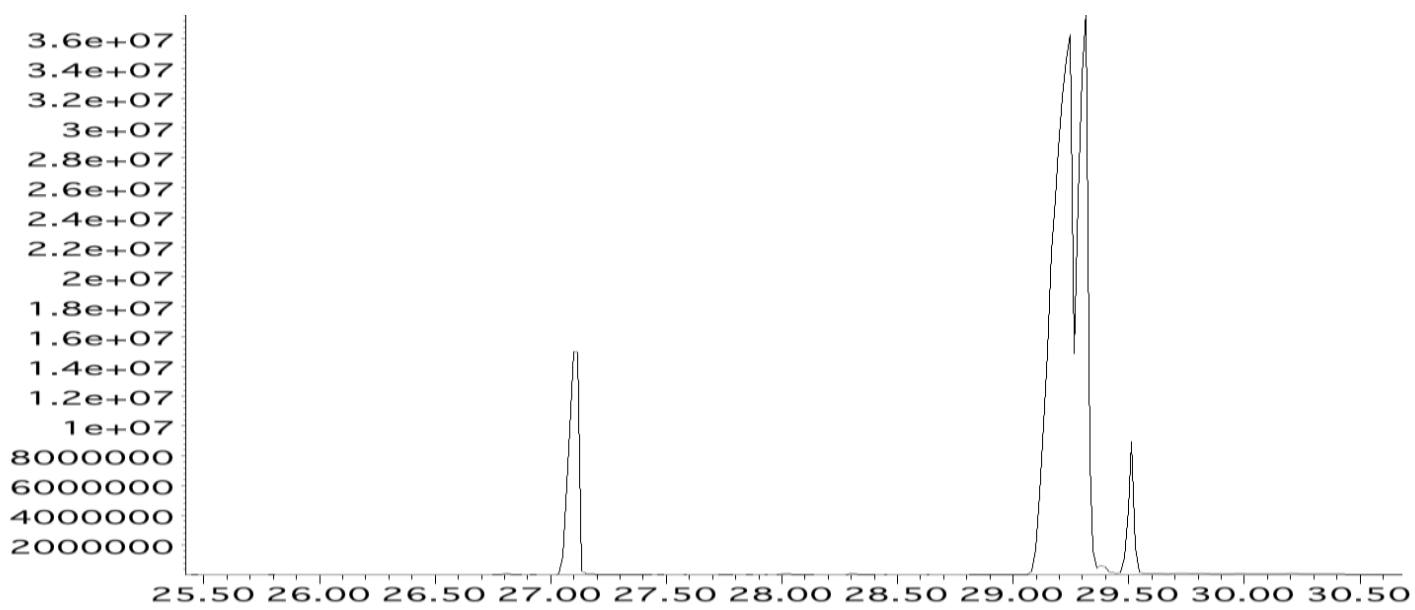

(b) Sonicated B100

Fig. 3.3. GC/MS results for untreated and sonicated biodiesel.

Table 3.1. Molecular Area Ion Counts for Biodiesel Methyl Esters

\begin{tabular}{|l|r|r|}
\hline \multicolumn{1}{|c|}{ Biodiesel Constituent } & Untreated & \multicolumn{1}{c|}{ Sonicated } \\
\hline Hexadecanoic Acid & 7472539 & 7170672 \\
\hline 9,12-Octadecadienoic Acid & 14799084 & 15169731 \\
\hline 9-Octadecenoic Acid & 2163726 & 2381758 \\
\hline Octadecanoic Acid & 3681575 & 3730697 \\
\hline
\end{tabular}




\section{CONCLUSIONS AND FUTURE WORK}

\subsection{CONCLUSIONS}

Sonication was observed to improve the filterability of neat biodiesel containing precipitates. The formation of precipitates as biodiesel is chilled to temperatures around $4^{\circ} \mathrm{C}$ has been observed to cause filter plugging in many field applications. A neat SME biodiesel was successfully spiked with precipitate precursors and chilled to initiate precipitate formation. Samples were briefly sonicated and the filtration time was determined using the ASTM D 7501 cold soak filtration standard. The action of sonication was found to reduce the filtration time to the original (pre-precipitate) value. The results clearly indicated that thermoviscous effects of the incoming sound waves were responsible for improved filtration time (and not bulk thermal heating).

\subsection{FUTURE WORK}

The authors of this study have filed an invention disclosure based on the successful experimental results. Although there is no future experimental work planned, we recommend further investigation to elucidate the influence of biodiesel blends to form precipitates and the effects of sonication on these blends to assess the effectiveness of the approach on blended diesel compositions. 


\section{REFERENCES}

1. M. E. Tat, J. H. VanGerpen, S. Soylu, M. Canikci, A. Monyem, and S. Wormley "The Speed of Sound and Isentropic Bulk Modulus of Biodiesel at $21^{\circ} \mathrm{C}$ form Atmospheric Pressure to $35 \mathrm{MPa}$," JAOCS, Vol. 77, no. 3 (2000) pp 285-289.

2. Biodiesel Technical Workshop (Oct 16-18, Chicago, Illinois). Sponsored by the National Biodiesel Board.

3. Fundamentals of Acoustics, $4^{\text {th }}$ edition. L. E. Kinsler, A. R. Frey, A. B. Coppens, and J. V. Sanders, published by John Wiley \& Sons, New York. 2000.

4. L. Pfalzgraf, I. Lee, J. Foster, and G. Poppe, "Effect of minor components of soy biodiesel on cloud point and filterability," Biorenewable Resources No. 4. September 2007. pp 17-21.

5. ASTM D7501-009b. Standard Test Method for Determination of Fuel Filter Blocking Potential of Biodiesel (B100) Blend Stock by Cold Soak Filtration Test (CSFT).

6. SG 1000 Technical Data Sheet http://www.soygold.com/products/solvents/SG1000/sg1000_techdata.htm

7. Kathy Radachi, personal communication. October 10, 2009. 